\title{
KONDISI HABITAT DAN KAITANNYA DENGAN JUMLAH PENYU HIJAU (Chelonia mydas) YANG BERSARANG DI PULAU DERAWAN, BERAU-KALIMANTAN TIMUR
}

\author{
Dharmadi') dan Ngurah Nyoman Wiadnyana1) \\ 1) Peneliti pada Pusat Riset Perikanan Tangkap, Ancol-Jakarta \\ Teregristrasi I tanggal: 24 Oktober 2007; Diterima setelah perbaikan tanggal: 30 Januari 2008; \\ Disetujui terbit tanggal: 7 April 2008
}

\begin{abstract}
ABSTRAK
Chelonia mydas merupakan spesies penyu yang paling umum dari 6 spesies yang ditemukan di Indonesia. Dewasa ini, jumlah penyu hijau banyak mengalami penurunan, karena berbagai faktor seperti ada perburuan dan pengambilan telur penyu secara ilegal, serta terjadi degradasi habitat. Dalam penelitian ini dipelajari kondisi habitat peneluran dan fluktuasi jumlah penyu hijau (Chelonia mydas) yang mendarat di Pulau Derawan, Kabupaten Berau-Kalimantan Timur, yang diharapkan dapat dijadikan sebagai bahan masukan bagi pengelolaan habitat penyu. Penelitian yang dilakukan pada bulan Maret dan September 2006 menggunakan metode survei dan pengamatan langsung di lapangan. Deskripsi dari habitat penyu bertelur adalah daratan luas dan landai yang terletak di atas bagian pantai dengan rata-rata kemiringan $30^{\circ}$ serta di atas pasang surut antara 30 sampai dengan $50 \mathrm{~m}$. Kondisi pantai berpasir tidak kurang dari $90 \%$ dan sisa debu maupun tanah liat dengan diameter butiran halus sampai dengan sedang. Jumlah penyu yang mendarat di Pulau Derawan 408 ekor pada tahun 2004 menurun menjadi 168 ekor pada tahun 2005. Penurunan jumlah penyu hijau (Chelonia mydas) yang mendarat di Pulau Derawan disebabkan oleh menurunnya kondisi lingkungan pantai akibat meningkatnya aktivitas masyarakat, berkurangnya kerapatan vegetasi pantai akibat abrasi, dan berkurangnya ruang tempat peneluran karena pembangunan rumah wisata di pinggir pantai di Pulau Derawan.
\end{abstract}

KATAKUNCI: habitat, penyu hijau, Pulau Derawan, Kalimantan Timur

ABSTRACT: Habitat condition and its relation to the number of green turtle (Chelonia mydas) nesting in Derawan Island, Berau-East Kalimantan. By: Dharmadi and Ngurah N. Wiadnyana

Green turtle is a most common of six turtles species found in Indonesia. Actualy, this turtle population has much decreased, due to some factors, such as turtle hunting and turtle eggs taking illegally as well as habitat degradation occurrence. The current work studied the condition of nesting habitat and the fluctuation of green turtle (Chelonia mydas) population landed in Derawan Island, Berau District in East Kalimantan, with hope that the results are usefull as input for better management of sea turtle habitat. The study that was conducted on March and September 2006 used survey methods and direct observation in the field. Habitat description of green turtle (Chelonia mydas) shows that the area for nesting is the sandy coast of less than $30^{\circ}$ slope, silt as well as compacted beach with small and medium grains diameter, and the difference between low and high tide is 30 to $50 \mathrm{~cm}$. Green turtle (Chelonia mydas) number in the nesting area of Derawan Island was 408 individuals in 2004 and decreased to about 168 individuals in 2005. This condition might be caused by the degradation of nesting habitat environment due to the increase of human activity, decrease of coastal vegetation density by coastal abration, and decrease of nesting habitat caused by the builts of housing and resort in the coastal area of Derawan Island.

KEYWORDS: nesting habitat, green turtle, Derawan Island, Berau, East Kalimantan

\section{PENDAHULUAN}

Seperti yang dikatakan oleh pakar di bidang penyu bahwa di dunia terdapat 7 jenis penyu dan 6 jenis antara lain dapat ditemukan di perairan Indonesia yaitu penyu belimbing (Dermochelys coriacea), penyu lekang (Lepidochelys olivacea), penyu sisik (Eretmochelys imbricata), penyu tempayan (Caretta caretta), penyu pipih (Natator depressus), dan penyu hijau (Chelonia mydas). Beberapa jenis penyu tersebut ditemukan juga di perairan negara-negara ASEAN (Abdullah et al., 2005). Salah satu jenis penyu yang paling banyak ditemukan di perairan Samudera Hindia, Kepulauan Riau, Kalimantan Barat, dan Kalimantan Timur adalah penyu hijau (Chelonia mydas) (Suwelo, 2005). 
Jenis penyu hijau (Chelonia mydas) yang dapat mencapai ukuran panjang $90 \mathrm{~cm}$ dengan bobot 150 $\mathrm{kg}$, adalah yang paling banyak diburu karena mempunyai nilai ekonomis paling tinggi antara lain 6 jenis penyu lain. Berdasarkan pada Peraturan Pemerintah No.7 tahun 1999 tentang pengawetan jenis tumbuhan dan satwa dan Peraturan Pemerintah No.8 tahun 1999 tentang pemanfaatan jenis tumbuhan dan satwa liar, penyu hijau (Chelonia mydas) baru dimasukan dalam daftar yang dilindungi. Hal ini, disebabkan oleh kenyataan di lapangan bahwa jumlah penyu hijau (Chelonia mydas) mengalami penurunan secara drastis akibat perburuan secara terus-menerus bahkan seringkali tertangkap nelayan yang menggunakan pancing maupun jaring. Tingkat eksploitasi yang tinggi dan perburuan secara intensif serta kerusakan habitat menyebabkan jumlah penyu hijau (Chelonia mydas) cenderung menurun setiap tahun. Jumlah produksi telur yang semakin rendah dari tahun ke tahun dan semakin sedikit jumlah penyu betina yang bertelur di berbagai lokasi peneluran merupakan kenyataan yang terjadi di lapangan (Nuitja, 1992).

Kebiasaan penyu adalah selalu bermigrasi dari satu pulau ke pulau lain (migratory species) karena hampir seluruh siklus hidup dihabiskan di laut lepas, mengarungi samudera luas melintasi batas teritorial suatu negara. Pada periode tertentu ketika musim bertelur tiba, kadang-kadang penyu betina akan mencari lokasi peneluran di pantai-pantai yang sesuai termasuk di perairan pantai pulau-pulau kecil yang terletak di daerah perbatasan satu negara dengan negara lain.

Pulau Derawan merupakan salah satu pulau yang memiliki habitat yang menarik bagi penyu untuk melakukan aktivitas bertelur. Dalam pembagian wilayah, pulau ini termasuk dalam Pemerintahan Daerah Kabupaten Berau, Kalimantan Timur yang terkenal sebagai daerah peneluran terbesar penyu hijau (Chelonia mydas) di Indonesia. Karena terjadi peningkatan penangkapan dan pengambilan telur penyu secara ilegal di Kepulauan Derawan menyebabkan berkurangnya jumlah biota tersebut. Selain itu, penurunan jumlah penyu dapat juga diakibatkan oleh kondisi habitat peneluran yang semakin mengkhawatirkan karena dampak dari berbagai aktivitas yang dilakukan oleh masyarakat setempat. Perburuan penyu semakin meningkat sejak 2 dekade terakhir, tidak hanya untuk memenuhi kebutuhan sehari-hari melainkan karena alasan komersial seperti permintaan konsumsi daging dan pemanfaatan bagian lain untuk ekspor yaitu dari daerah Bali, Ambon, dan Ujung Pandang (Salm \&
Halim, 1984; Schulz, 1984). Informasi tentang karakteristik habitat peneluran dan jumlah penyu hijau sampai dengan saat ini relatif sedikit, oleh karena itu penelitian ini dilakukan dengan tujuan untuk mempelajari kondisi habitat peneluran dan fluktuasi jumlah penyu hijau (Chelonia mydas) yang bersarang di Pulau Derawan, Kabupaten Berau-Kalimantan Timur. Kajian ini diharapkan dapat dijadikan sebagai bahan masukan bagi pengelolaan habitat penyu, khususnya di Pulau Derawan dan sekitar.

\section{BAHAN DAN METODE}

Pengamatan lapangan untuk pengumpulan data habitat penyu dilakukan pada bulan Maret (yang mewakili musim penghujan) dan bulan September (yang mewakili musim kemarau) tahun 2006 di Derawan Kabupaten Berau, Kalimantan Timur (Gambar 1). Metode penelitian yang digunakan adalah survei melalui pengamatan langsung di lapangan. Untuk mengetahui karakteristik habitat dilakukan pencatatan kondisi sekitar pantai lokasi peneluran penyu hijau (Chelonia mydas) yang meliputi topografi pantai, jenis-jenis tanaman pantai, dan kondisi lingkungan sekitar pantai. Sedangkan untuk mengetahui jumlah penyu yang mendarat untuk bertelur dilakukan pencatatan data harian yang diperoleh dari petugas lapangan (observer) dan berdasarkan pada data sekunder yang dihimpun dari Stasiun Pengawasan Hutan dan Perlindungan Alam, Dinas Perikanan dan Kalautan Kabupaten Berau yang bekerjasama dengan The Nature Conservation. Data yang dihimpun mencakup periode tahun 2004 dan 2005 dianalisis secara deskriptif.

\section{HASIL DAN BAHASAN}

\section{Kondisi Habitat Peneluran}

\section{Topografi Pantai}

Berdasarkan pada hasil pengamatan langsung di lapangan, tampak bahwa di Pulau Derawan terdapat beberapa titik lokasi peneluran penyu hijau (Chelonia mydas) yang berada dalam kisaran jarak antara 30 sampai dengan $50 \mathrm{~m}$ di atas batas pasang surut. Panjang pantai peneluran di daerah ini sekitar 1 sampai dengan $2 \mathrm{~km}$. Kondisi pantai yang landai dan memiliki pasir halus dapat memudahkan penyu menuju daratan untuk mencari lokasi dan membuat lubang sebagai tempat peneluran. Menurut Suwelo \& Somantri (1989) untuk tempat bertelur, penyu memilih dataran pasir yang agak miring dengan lebar antara 30 sampai dengan $60 \mathrm{~m}$ dari pasang terendah dan banyak ditumbuhi pohon pandan, Pandanus tectorius. 


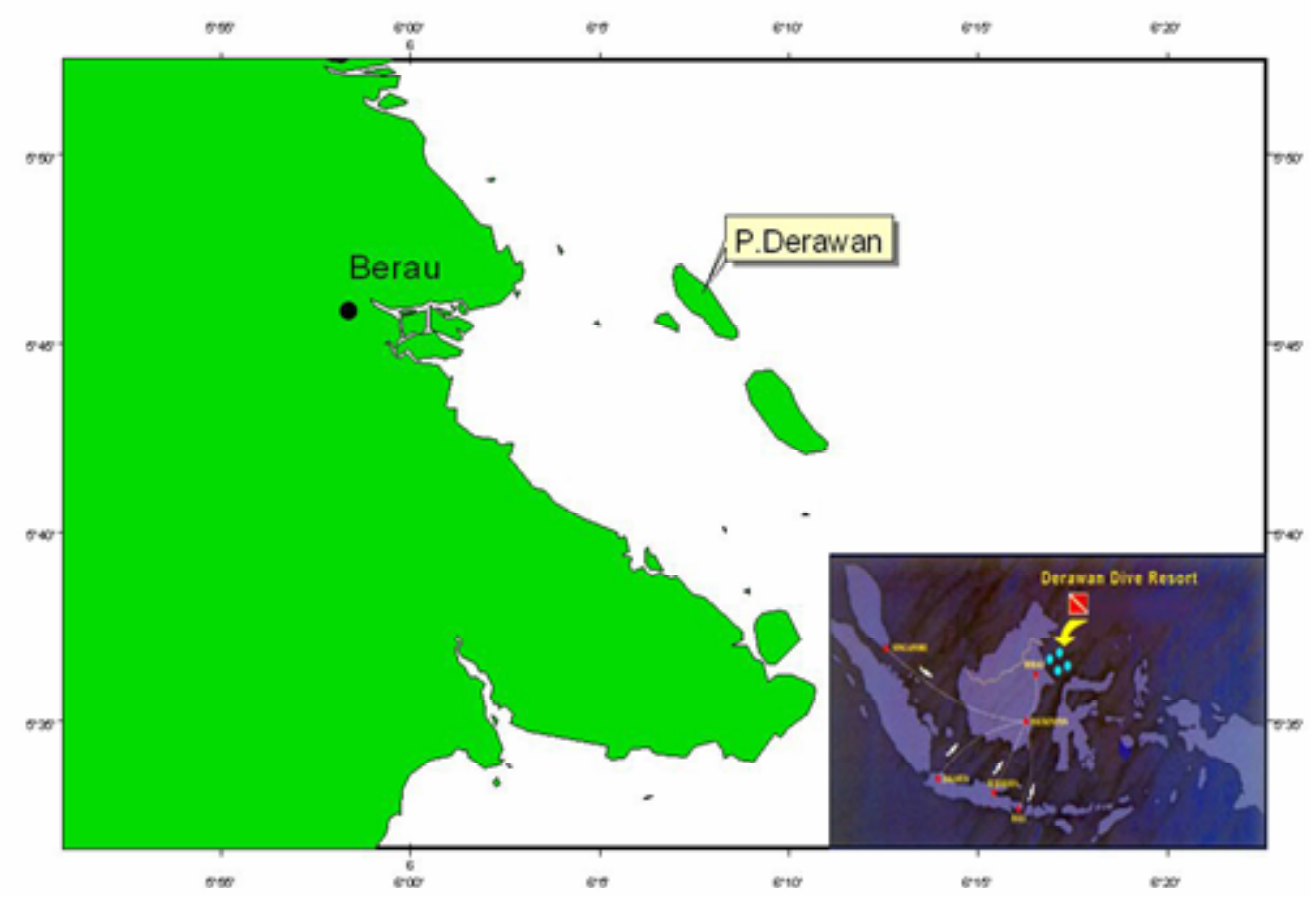

Gambar 1. Lokasi penelitian penyu hijau (Chelonia mydas) di Pulau Derawan, Berau-Kalimantan.

Figure 1. Research location of green turtle (Chelonia mydas) in Derawan Island, Berau-Kalimantan.

Kemiringan pantai sangat berpengaruh pada banyak penyu yang akan mendarat dan membuat sarang. Menurut Burstad vide Nuitja (1992) semakin curam pantai, akan semakin menyulitkan bagi penyu untuk melihat obyek yang lebih jauh di depan karena mata penyu hanya mampu melihat dengan baik pada sudut $150^{\circ}$ ke arah bawah. Suwelo (2005) mengatakan bahwa habitat penyu yang digunakan untuk mengeluarkan telur adalah daratan luas dan landai dengan rata-rata kemiringan $30^{\circ}$ dan di atas pasang surut antara 30 sampai dengan $80 \mathrm{~m}$. Di daerah subtidal ditemukan tumbuhan algae dan rumput laut yang menjadi pakan penyu. Daerah intertidal yang mendapat pasang surut air laut jarang ditemukan sarang penyu, sedangkan pada daerah supratidal merupakan daerah yang baik dan cocok bagi pengeraman dan penetasan telur penyu hijau (Chelonia mydas) (Nuitja, 1992).

\section{Vegetasi Pantai}

Faktor ekologi yang dapat mempengaruhi penyu hijau (Chelonia mydas) untuk melakukan peneluran di pantai yaitu ada jenis vegetasi pandan laut dan kondisi hutan pantai yang cukup rimbun. Jenis vegetasi yang terdapat pada daerah pantai Pulau Derawan sebagai tempat bertelur penyu adalah bintaro (Tournefortia argenta), pandan laut (Pandanus tectorius), waru laut (Hibiscus tiliaceus), ketapang (Terminalia catappa), nyamplung (Calophyllum), lampeni (Ardisia humilis), dan tumbuhan merambat seperti rumput kakawatan (Cynodon dactylon), dan rumput angin (Spinifex littoralis). Menurut Suwelo (1988) tekstur pasir yang relatif halus, vegetasi pantai yang didominasi oleh jenis tanaman kangkung laut (Ipomea pescaprae) yang merambat, pandan laut (Pandanus tectorius), serta waru laut (Thespesia populnea) merupakan habitat yang disukai oleh penyu hijau (Chelonia mydas) sebagai lokasi peneluran. Kondisi vegetasi di Pulau Derawan adalah dijumpai beberapa jenis vegetasi tersebut di atas dengan kerapatan antara 2 sampai dengan $3 \mathrm{~m}$. Menurut Suwelo et al. (1985) kondisi vegetasi pantai yang utuh akan memberikan kesuburan perairan melalui rembesan dari serasah dari air hujan sehingga rumput laut tumbuh subur dan akan mengundang penyu menuju tempat tersebut. Sedangkan vegetasi pantai yang rusak menyebabkan erosi pasir pantai dan memacu pertumbuhan tanaman menjalar dan sehingga makin mempersempit lokasi peneluran.

\section{Kondisi Lingkungan Sekitar Pantai}

Kondisi pantai sebagai lokasi bertelur penyu hijau (Chelonia mydas) di Pulau Derawan terdapat tumbuhan vegetasi pantai atau tanaman kelapa atau bahkan di beberapa lokasi yang juga merupakan tempat bertelur penyu hijau (Chelonia mydas) tidak dijumpai tanaman sama sekali. Hal ini, menunjukkan bahwa pantai yang terdapat atau tidak ada tanaman sama sekali bukan merupakan faktor penghalang bagi 
penyu untuk bertelur, khususnya yang terjadi di Pulau Derawan.

Berdasarkan pada pengamatan langsung dan informasi dari staf WWF yang bertugas untuk memonitor kegiatan peneluran penyu, bahwa di Pulau Derawan penyu hijau (Chelonia mydas) dapat bertelur pada berbagai kondisi yang berbeda. Proses peneluran dapat dilakukan di dekat pohon kelapa, sekitar tanaman pantai yang rimbun, di bawah rongsokan perahu, bahkan dapat dilakukan di pelataran pantai (Gambar 2). Lokasi peneluran penyu hijau (Chelonia mydas) di Pulau Derawan juga dijumpai di depan halaman rumah yang dibangun di pinggiran pantai. Gambar tersebut merupakan lokasi peneluran yang telah diambil telur oleh petugas untuk dipindahkan ke lokasi penetasan yang terkontrol (Gambar 3). Kondisi yang demikian mencerminkan bahwa tingkah laku penyu relatif tidak berubah terhadap habitat yang ada di mana penyu-penyu telah melakukan aktivitas bertelur.
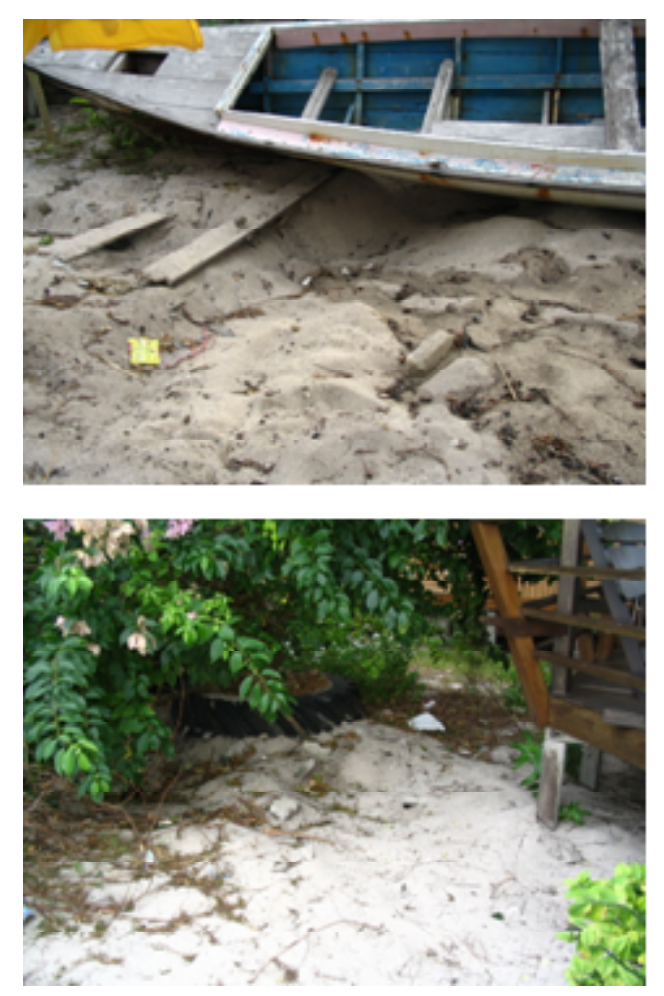

Di lokasi yang berbeda, Fitriyanto (2006) mengatakan bahwa di Pulau Sangalaki yang lokasinya berdekatan dengan Pulau Derawan, terjadi tingkah laku penyu hijau (Chelonia mydas) dalam kondisi tertentu menyebabkan biota tersebut menjadi tidak menghiraukan halangan yang ada di depan dan terus bergerak ke arah lokasi peneluran walaupun menaiki bongkahan kayu. Kondisi demikian dapat terjadi apabila penyu berada dalam keadaan terdesak dan segera mengeluarkan telur. Idealnya dalam proses pengeluaran telur penyu ada beberapa faktor yang dapat mendukung aktivitas tersebut seperti suasana yang sunyi, tidak terdapat penyinaran dan tidak ada aktivitas pergerakan yang dapat mengganggu penyu menuju ke pantai. Longdy (2003) mengatakan bahwa apabila di pantai ada aktivitas manusia yang dapat mengganggu kegiatan penyu untuk bertelur, maka penyu akan mencari daerah pantai lain yang dirasakan aman bagi penyu untuk membuat sarang dan melakukan peneluran. Menurut Nuitja (1992) penyu betina yang akan melakukan proses bertelur sangat peka terhadap cahaya.
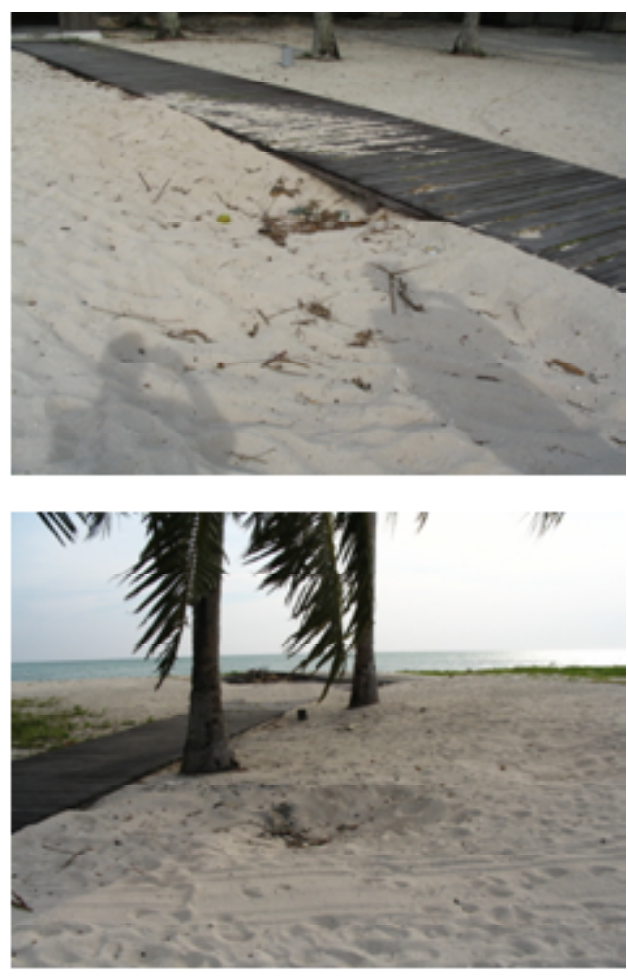

Gambar 2. Kondisi pantai lokasi bertelur penyu hijau (Chelonia mydas) di Pulau Derawan, Kabupaten Berau-Kalimantan Timur.

Figure 2. Nesting area condition of green turtle (Chelonia mydas) in Derawan island, Berau RegencyEast Kalimantan. 

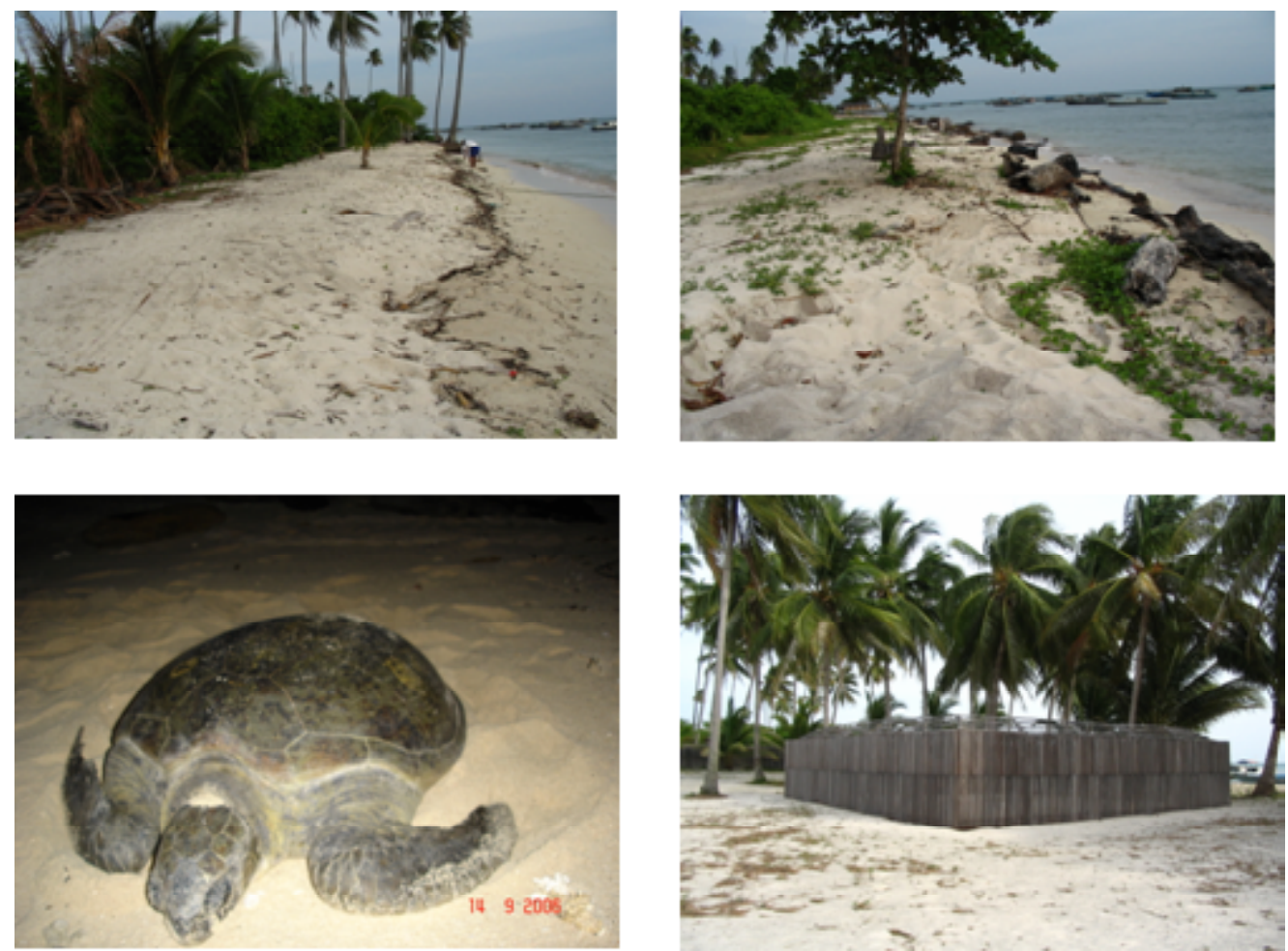

Gambar 3.

Penyu hijau (Chelonia mydas) dan tempat penetasan telur.

Figure 3. Green turtle (Chelonia mydas) and nesting area.

Daerah peneluran sebagai ruang tempat bertelur bagi penyu hijau (Chelonia mydas), mempunyai karakteristik yang menarik naluri penyu untuk membuat sarang. Suwelo et al. (1985) mengatakan bahwa penyu hijau (Chelonia mydas) bertelur pada berbagai tipe pantai dengan persyaratan sebagai berikut mudah dicapai dari laut, tidak dapat dicapai oleh air laut saat pasang, pantai berpasir dengan tersedia udara dan kelembaban yang cukup serta dengan suhu antara 20 sampai dengan $27^{\circ} \mathrm{C}$ agar selama dalam proses pembuatan sarang tidak terlalu mengalami penurunan. Bustard vide Nuitja (1992) mengatakan bahwa penyu hijau (Chelonia mydas) menyukai pantai berpasir tebal yang landai dengan butiran pasir yang halus berdiameter antara 0,28 sampai dengan $0,31 \mathrm{~mm}$ dengan latar belakang hutan lebat. Lebih lanjut Nuitja (1992) mengatakan bahwa penyu hijau (Chelonia mydas) pada umumnya memilih pantai peneluran yang cukup luas dan landai dengan kemiringan rata-rata $30^{\circ}$ dan berada di daerah berjarak 30 sampai dengan $80 \mathrm{~m}$ di atas batas pasung surut. Selain itu, secara naluriah penyu memilih pasir yang mudah digali dan cukup lembab serta memiliki diameter butiran pasir tertentu untuk meletakkan telurtelur (Gambar 4). Penyu hijau (Chelonia mydas) cenderung membuat sarang di bawah naungan pohon pandan laut, karena sistem perakaran pandan laut meningkatkan kelembaban pasir, memberikan kestabilan pada pasir, dan memberi rasa aman pada penyu saat melakukan penggalian sarang (Suwelo et al., 1985).

Semakin curam pantai, semakin sulit bagi penyu untuk melihat obyek yang berada jauh di depan karena mata penyu mampu melihat dengan baik pada sudut $150^{\circ}$ ke arah bawah (Bustard dalam Nuitja (1992). Suhu pasir juga sangat berpengaruh terhadap proses peneluran dan penetasan penyu, suhu pasir yang terlalu tinggi $\left(>35^{\circ}\right)$ akan menyulitkan penyu untuk membuat sarang, sedang apabila suhu terlalu rendah $\left(<25^{\circ}\right)$ akan berpengaruh terhadap masa inkubasi dan tingkat keberhasilan telur menetas. Ackerman vide Yasuda et al. (2005) mengatakan bahwa di Thailand penyu hijau (Chelonia mydas) dapat mentolerir suhu antara 25 sampai dengan $27^{\circ} \mathrm{C}$ dan 33 sampai dengan $35^{\circ} \mathrm{C}$. Suhu antara 31 sampai dengan $33^{\circ} \mathrm{C}$ menghasilkan lebih dari $96 \%$ telur yang menetas. Sedangkan suhu di bawah $25^{\circ} \mathrm{C}$ dan di atas $33^{\circ} \mathrm{C}$ tidak sesuai bagi penyu hijau (Chelonia mydas) untuk menetaskan telur (Abdullah \& Ismail, 2004). Menurut Mrosovsky \& Yntema dalam Liew et al. (2002) perubahan suhu 1 sampai dengan $2^{\circ} \mathrm{C}$ dapat memberikan pengaruh perbedaan pada rasio kelamin saat proses penetasan. Ada beberapa faktor yang dapat mempengaruhi perubahan kisaran suhu pada penetasan penyu hijau (Chelonia mydas) yaitu kondisi 


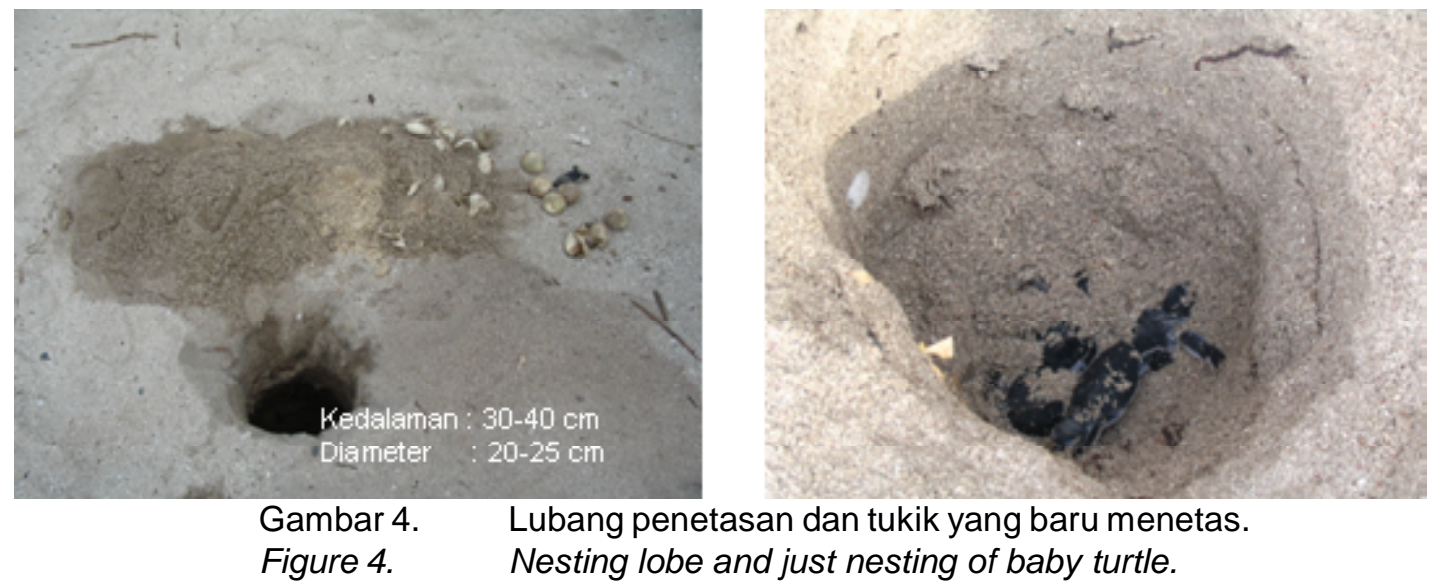

iklim, pasir dan karakter pantai, vegetasi, stabilitas air, dan pemanasan saat proses metabolisme pada telur.

Suhu rendah terjadi karena intrusi air laut akibat tergenang air pasang dan curahan hujan yang berlebihan. Tidak semua pasir dapat digunakan untuk bertelur, tempat yang diinginkan memiliki butiran pasir tertentu yang mudah digali dan secara naluriah dianggap aman untuk bertelur. Susunan tekstur daerah peneluran berupa pasir tidak $<90 \%$ dan sisa debu maupun liat dengan diameter butiran berbentuk halus dan sedang. Tipe pantai untuk syarat bertelur yaitu mudah dicapai dari laut, tidak dapat dicapai oleh air pasang, pantai berpasir, tersedia udara dan kelembaban yang cukup, serta pantai tidak mengalami penurunan atau longsor selama pembuatan sarang. Semua jenis penyu menyukai bagian laut yang dangkal dan terdapat tumbuhan. Bagian laut tidak dalam dan terbuka, dasar pantai ditumbuhi jenis rumput laut, sedikit berbatu yang digunakan untuk tempat istirahat (Bjorudal, 1995).

\section{Jumlah Penyu yang Bersarang di Pulau Derawan}

Jumlah penyu di Pulau Derawan Kabupaten BerauKalimantan Timur disajikan pada Gambar 5 yang memperlihatkan fluktuasi bulanan jumlah penyu yang mendarat dan bertelur di pantai ke-2 pulau tersebut dari tahun 2003 sampai dengan 2005. Pada gambar dijelaskan bahwa penyu hijau (Chelonia mydas) yang mendarat ke pantai dan melakukan peneluran terjadi setiap bulan, rata-rata penyu mendarat pada periode berbeda adalah sama yaitu 8,3\% atau 50 ekor per bulan (tahun 2004) dan 24 ekor per bulan (tahun 2005) dari jumlah total penyu betina yang mendarat. Musim peneluran penyu laut berbeda antara satu spesies dengan spesies lain (Phan, 2003). Puncak musim bertelur penyu di Pulau Derawan berlangsung pada bulan April sampai dengan Juni. Jumlah penyu yang mendarat di pantai Pulau Derawan untuk keperluan bertelur tercatat 408 ekor pada tahun 2004 dan menurun menjadi 168 ekor pada tahun 2005. Berdasarkan pada laporan masyarakat di Pulau Derawan selama 5 tahun terakhir aktivitas penangkapan penyu yang dilakukan secara sengaja oleh nelayan pendatang terjadi 3 sampai dengan 4 kali. Aktivitas penangkapan ikan di lokasi sekitar habitat penyu yang dilakukan dengan menggunakan bahan berbahaya seperti bom, mengakibatkan terjadinya kematian penyu per bulan 1 sampai dengan 2 ekor. Bahkan informasi terakhir tentang pencurian penyu di perairan Indonesia telah dilakukan oleh kapal Cina yang menangkap penyu secara sengaja di perairan Pulau Maratua Kabupaten Berau yang terjadi pada tanggal 8 Mei 2007, hasil tangkapan penyu 387 ekor terdiri atas 296 ekor penyu sisik (Eretmochelys imbricata), 90 ekor penyu hijau (Chelonia mydas), dan 1 ekor penyu tempayan (Caretta caretta) (Dinas Kelautan dan Perikanan Kabupaten Berau, 2008). Aktivitas tersebut telah melanggar Peraturan Pemerintah berdasarkan pada Undang-Undang No.31 tahun 2004 tentang perikanan (pasal 81) yaitu pelarangan menangkap udang atau ikan menggunakan potasium atau racun, setrum listrik, bahan peledak, dan alat lain yang merugikan atau membahayakan kelestarian sumber daya ikan sesuai peraturan atau perundangan yang berlaku.

Menurunnya jumlah penyu hijau (Chelonia mydas) yang bersarang di Pulau Derawan juga disebabkan oleh beberapa faktor lain yaitu ada bangunan di tepi pantai yang diperuntukan bagi wisatawan yang akan melihat langsung proses peneluran dan penetasan penyu hijau (Chelonia mydas). Bangunan-bangunan tersebut secara langsung akan mengurangi lahan tempat peneluran. Ada lokasi penambatan perahu nelayan yang berdekatan dengan lokasi pendaratan penyu hijau (Chelonia mydas) dan terdapat bongkahan-bongkahan kayu yang terdampar di pinggir pantai yang dapat menghalangi penyu hijau (Chelonia 
mydas) untuk membuat sarang dan bertelur. Selain itu, berkurangnya vegetasi pantai akibat abrasi juga dapat mempengaruhi penyu hijau (Chelonia mydas) untuk bersarang. Jumlah penyu hijau (Chelonia mydas) yang bersarang juga dapat dipengaruhi oleh keberadaan predator alami seperti kadal, biawak, tikus, kepiting, burung laut, dan ikan karnivora. Karena beberapa jenis biota tersebut seperti kadal, biawak, dan tikus dapat mendeteksi keberadaan telur-telur penyu dan memangsanya meskipun tertutup atau tertimbun pasir. Sedangkan tukik (anak penyu) yang baru dilepas ke laut untuk tujuan pengkayaan stok terancam oleh burung laut, kepiting, maupun ikanikan karnivor. Sehingga semua jenis predator tersebut merupakan ancaman bagi kelangsungan hidup. Ahmad \& Kamarrudin (2003) mengatakan bahwa persentase kematian tukik yang baru menetas yang dipelihara dalam ruang terkontrol, karena pemangsaan kepiting antara 22 sampai dengan $50 \%$. Sedangkan Witzell vide Ahmad \& Kamarruddin (2003) mengatakan bahwa tukik yang baru dilepas ke habitat alami akan mudah dimangsa oleh ikan kerapu (Promicrops lancelotus) selama periode adaptasi di laut.

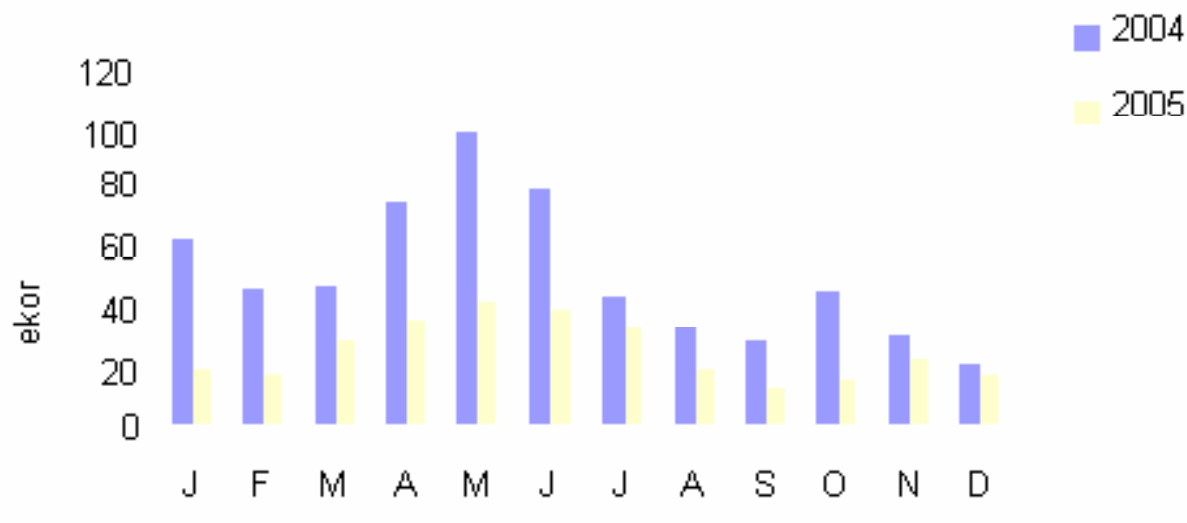

Gambar 5. Fluktuasi bulanan jumlah penyu hijau (Chelonia mydas) yang mendarat di Pulau Derawan, tahun 2004 sampai dengan 2005.

Figure 5. Monthly fluctuation number of green turtle (Chelonia mydas) that landed at Derawan Island during, 2004 to 2005.

Secara umum, beberapa penyebab penurunan jumlah penyu dapat dikelompokkan menjadi 3 (Anonimus, 2003) sebagai berikut 1) terjadi pengambilan penyu dewasa terutama untuk diperdagangkan di Bali; 2) ada aktivitas perikanan, hal ini karena banyak komunitas masyarakat pesisir di Indonesia yang tergantung dari sumber daya laut sebagai sumber pendapatan dan dari penyu yang mati atau terluka pada saat aktivitas penangkapan ikan atau biota lain, termasuk ada informasi masyarakat yang menemukan penyu mati dalam jaring nelayan; dan 3) penggunaan jaring traw/juga merupakan salah satu penyebab menurun jumlah penyu di laut.

Penurunan jumlah penyu hijau (Chelonia mydas) yang bersarang di Pulau Derawan dari tahun 2004 dan 2005 , ternyata juga diikuti oleh penurunan persentase telur yang menetas pada periode yang sama (Gambar 6). Persentase bulanan telur yang menetas relatif stabil yaitu berkisar antara 55 sampai dengan $73 \%$ pada tahun 2004 dan 47 sampai dengan $67 \%$ pada tahun 2005. Beberapa faktor yang mempengaruhi keberhasilan dalam proses penetasan telur penyu adalah suhu, kelembaban dan kondisi lingkungan, salinitas, predasi, dan abrasi pantai (Ibrahim et al., 2003; Ali et al., 2004), microorganisms (Frick vide Merwe et al., 2003) dan faktor penanganan telur dalam hatcheri (Limpus et al. vide Merwe et al., 2003).

Faktor lain yang diduga dapat mengakibatkan kegagalan penetasan telur penyu adalah curah hujan dan lokasi sarang. Lokasi peneluran yang dijumpai di bawah pohon pandan yang rimbun, kemungkinan besar akan mengalami kegagalan dalam proses penetasan. Hal ini, disebabkan karena sarang telur penyu tersebut kurang mendapat sinar matahari dan jika musim hujan akan mendapat curah hujan secara berlebihan 
sehingga akan mempengaruhi kestabilan suhu. Menurut Nuitja (1992) suhu mempunyai peranan sangat penting dalam menentukan lama atau tidak masa inkubasi telur penyu. Sarang telur penyu dengan masa inkubasi lama (lebih dari 50 sampai dengan 60 hari) akan memperkecil persentase keberhasilan penetasan.

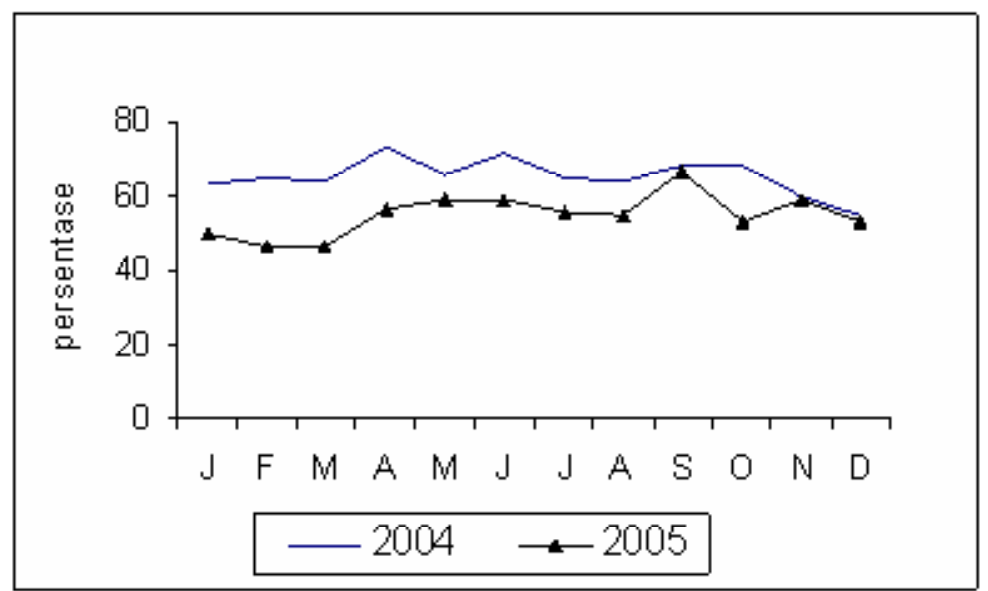

Gambar 6. Persentase jumlah telur menetas pada penyu hijau (Chelonia mydas) di Pulau Derawan selama tahun 2004 dan 2005.

Figure 6. Percentage number of egg nesting green turtle (Chelonia mydas) at Derawan Island during 2004 and 2005.

Pelestarian penyu sebagai binatang reptilia khas Kabupaten Berau perlu mendapat perhatian, khususnya untuk pelestarian jumlah dan peningkatan produksi telur. Untuk menjaga dan meningkatkan kelangsungan hidup tukik di laut yang sering terancam oleh predator alami, perlu diambil langkahlangkah yang tepat seperti pembuatan tempat-tempat penetasan buatan yang bersifat semi alami (Gambar 3) dan penebaran tukik di perairan yang berkarang sehingga tukik yang baru dilepaskan dapat bersembunyi. Upaya ini telah dilakukan oleh Pemerintah Daerah Kabupaten Berau yang telah melakukan penebaran tukik di Pulau Balikukup dekat Pulau Manimbora di Karang Mangkalasa perairan Pulau Derawan masing-masing 1.000 ekor. Di samping itu, untuk mendukung program pelestarian penyu, beberapa peraturan dan keputusan daerah telah dikeluarkan seperti Peraturan Bupati Berau No.31 tahun 2005 tentang kawasan konservasi Laut Berau, di mana telah ditetapkan perairan pesisir dan laut Kabupaten Berau seluas 1,2 juta ha telah ditetapkan sebagai kawasan konservasi laut dan S. K. Mentan No.604/Kpts/um/1982 tentang penetapan Pulau Sangalaki dan Pulau Semama sebagai kawasan konservasi laut sebagai taman laut dan cagar alam laut (Pemerintah Daerah Berau, 2002).

\section{KESIMPULAN}

Secara fisik, pantai Pulau Derawan memungkinkan sebagai tempat pembuatan sarang dan peneluran penyu hijau (Chelonia mydas). Jumlah penyu yang mendarat mengalami penurunan, pada tahun 2004 tercatat 408 ekor kemudian menurun menjadi 168 ekor pada tahun 2005. Secara ideal, dalam proses pengeluaran telur penyu ada beberapa faktor yang dapat mendukung aktivitas tersebut seperti suasana yang sunyi, tidak terdapat penyinaran dan tidak ada aktivitas pergerakan yang dapat mengganggu penyu menuju ke pantai. Pada kondisi apabila penyu berada dalam keadaan terdesak dan segera mengeluarkan telur, kadang-kadang faktor tersebut tidak menjadi halangan dan penyu akan terus bergerak ke arah lokasi peneluran kendati menghindari bongkahan kayu yang terdampar di pantai.

\section{SARAN}

Untuk memulihkan jumlah penyu hijau (Chelonia mydas) yang bersarang di Pulau Derawan, disarankan Pemerintah Daerah setempat perlu mengupayakan beberapa hal sebagai berikut:

1. Mengurangi penerangan lampu bangunan wisata pada malam hari, karena cahaya lampu dapat mengganggu aktivitas penyu untuk mendarat.

2. Melakukan kegiatan secara rutin dengan membersihkan pantai dari barang-barang yang terdampar seperti bongkahan kayu dan sampahsampah organik lain sehingga tidak menghalangi penyu untuk mencari tempat bertelur. 
3. Merelokasi perahu-perahu nelayan yang menambatkan perahu di wilayah yang berdekatan dengan wilayah habitat peneluran penyu.

4. Secara periodik, melakukan penyuluhan pada masyarakat setempat maupun masyarakat sekitar pulau tersebut akan pentingnya pelestarian penyu dan melakukan pengawasan habitat penyu di perairan Pulau Derawan dan sekitar dari aktivitas penangkapan ikan atau biota lain secara illegal.

\section{PERSANTUNAN}

Kegiatan dari hasil riset inventarisasi mamalia air (pesut), penyu, dan labi-labi, T. A. 2006, di Pusat Riset Perikanan Tangkap, Ancol-Jakarta.

\section{DAFTAR PUSTAKA}

Abdullah, S. \& M. Ismail. 2004. Temperature dependent sex determination and hatching performance of green turtles (Chelonia mydas) at Chendor Rookery on the east coast of Peninsular Malaysia. Proceedings of the International Symposium on SEASTAR2000 and Biologging Science. Bangkok. 11-15 p.

Abdullah, S., T. Zulkifli, \& I. Mazlan. 2005. Tagging study of green turtles (Chelonia mydas) on the East Coast of Peninsular Malaysia. Procedings of the $2^{\text {nd }}$ International symposium on SEASTAR2000 and Asean Biologging Science (The $6^{\text {th }}$ SEASTAR2000 Workshop). Bangkok. p. 89-92.

Ahmad, A. \& I. Kamarruddin. 2003. Crab predation on green turtle (Chelonia mydas) eggs incubated on a natural beach and in turtle hatcheries. Proceedings of the 3rd Workshop on SEASTAR2000. Bangkok. p 95-100.

Ali, A, K. K. K. Yaacob, S. A. Razak, \& Z. Talib. 2005. Individual nest site preference of green turtle (Chelonia mydas) on Mak Kepit beach and its relation with hatching emergence success. Proceedings of the International Symposium on SEASTAR2000 and Biologging Science. Bangkok. $45-49 \mathrm{p}$.

Anonimus. 2003. Pedoman pengelolaan konservasi penyu dan habitatnya. Direktorat Konservasi dan Taman Nasional. Direktorat Jenderal Pesisir dan Pulau-Pulau Kecil. Departemen Kelautan dan Perikanan. 45 hal.
Bjorudal, K. A. 1995. Biology and Conservation of Sea Turtle. Journal Smiotsonian Institution Press. Washington, D. C. 615 p.

Fitriyanto, A. 2006. Studi habitat penyu hijau (Chelonia mydas) dan upaya pelestariannya di Pulau Sangalaki, Kabupaten Berau-Kalimantan Timur. Laporan Praktek Integrasi. Program Studi Teknologi Pengelolaan Sumber Daya Perairan Jurusan Teknologi Pengelolaan Sumber Daya Perairan. Sekolah Tinggi Perikanan. Jakarta. 65 hal.

Ibrahim, K., Jason V. de M., \& W. Joan. 2003. Full or split clutches-which strategy should be adopted in managing marine turtle hatchling production? Proceedings of the $3^{\text {rd }}$ Workshop on SEASTAR2000. Bangkok. p. 111-114.

Liew, H. C., K. Tatsukawa, S. L. Chan, E. H. Chan, M. Charuchinda, \& K. Ibrahim. 2002. Clutch size and incubation temperatures of green turtle eggs. Proceedings of the $3^{\text {rd }}$ Workshop on SEASTAR2000. Bangkok. 101-104 p.

Longdy, V. 2003. Sea turtle distribution and nesting ground in Cambodia. Proceedings of the $3^{\text {rd }}$ Workshop on SEASTAR2000. Bangkok. p. 121123.

Merwe, J., I. Kamarruddin, I. Michaela, \& W. Joan. 2003. Effects of hatchery nest density on the emergence success and quality of Chelonia mydas hatchling. Proceedings of the $3^{\text {rd }}$ Workshop on SEASTAR2000. Bangkok. p. 115-120.

Nuitja. 1992. Biologi dan ekologi pelestarian penyu laut. Institut Pertanian Bogor. Bogor.

Phan, H. D. 2003. The challenges and oppotunities for research, management, and conservation on sea turtles in Vietnam. Proceedings of the $3^{\text {rd }}$ Workshop on SEASTAR2000. Bangkok. p.13-21.

Pemerintah Daerah Berau. 2002. Laporan Pengawasan dan Pengamanan Konservasi Penyu. BAPELDA. Berau.

Salm, R. \& M. H. Halim. 1984. Marine conservation data atlas Indonesia. Planning of the Survival of Indonesia's Seas and Ccoasts. IUCN/WWF Project 3108 Marine Conservation. Prepared for Directorate General of Forest Protection and Nature Conservation. Bogor. Indonesia. 29 maps. Text. 
Schuld. 1984. Turtle conservation strategy in Indonesia. Field Report. No.6. Marine Conservation. Bogor. $99 \mathrm{p}$.

Suwelo, I. S., A. Somantri, \& U. M. Hasan. 1985. Usaha rehabilitasi penyu di Pangumbahan dengan penetasan telur. Departemen Kehutanan. Pusat Pendidikan dan Pelatihan Kehutanan. Bogor. 11 hal.

Suwelo, I. S. 1988. Hawksbill turtle protection and utilization. Paper Presented at the Workshop on Sea Turtle Ranching. Japan. 1-3 August 1988. 5 hal.
Suwelo, I. S. 2005. Kumpulan tulisan ilmiah atau semi ilmiah tentang konservasi penyu dan habitatnya. Yayasan Kelestarian Penyu Indonesia.

Wiadnyana, N. N., M. Boer, F. Satria, Mahiswara, \& R. T. Mahulette. 2007. Estimasi hasil tangkapan penyu laut yang tidak sengaja oleh perikanan tuna long line di perairan Indonesia (in preparition).

Yasuda, T., K. Kongkiat, K. Winai, \& Nobuaki. 2005. Seasonal nesting of green turtles at Huyong Island, Thailand. Procedings of the $2^{\text {nd }}$ International Symposium on SEASTAR2000 and Asean Biologging Science (The $6^{\text {th }}$ SEASTAR2000 workshop). Bangkok. p. 51-54. 